\title{
Similar survival benefits of a good response and stable disease to platinum-based chemotherapy in non-small cell lung cancer
}

\author{
TOMOHIRO TAMURA ${ }^{1}$, KOICHI KURISHIMA ${ }^{2}$, KENSUKE NAKAZAWA ${ }^{1}$, \\ HIROICHI ISHIKAWA ${ }^{2}$, HIROAKI SATOH ${ }^{3}$ and NOBUYUKI HIZAWA ${ }^{1}$
${ }^{1}$ Division of Respiratory Medicine, Faculty of Medicine, University of Tsukuba; ${ }^{2}$ Division of Respiratory Medicine, Tsukuba Medical Center Hospital, Tsukuba; ${ }^{3}$ Division of Respiratory Medicine, Mito Medical Center, University of Tsukuba, Mito, Ibaraki, Japan

Received August 26, 2014; Accepted May 8, 2015

DOI: $10.3892 / 01.2015 .3350$

\begin{abstract}
The present study aimed to evaluate the similar survival benefits of a good response [complete response or partial response (CR/PR)] and stable disease (SD) to chemotherapy in non-small cell lung cancer (NSCLC) patients in clinical practice. All 322 patients who were treated between 1999 and 2012 with first-line platinum-based chemotherapy were retrospectively analyzed. Tumor responses were classified according to the response evaluation criteria for solid tumors. A total of 67 (20.8\%) patients experienced CR/PR and 165 (51.2\%) achieved SD. There was no difference in progression-free survival between the patients with $\mathrm{CR} / \mathrm{PR}$ and those with SD $(\mathrm{P}=0.347)$. There was also no difference between the two groups with regard to overall survival time $(\mathrm{P}=0.878)$. In multivariate analysis, disease-control (more than SD) was one of the favorable prognostic factors. In clinical practice, a survival benefit would be provided not only for the patients who have good response, but also for those with SD.
\end{abstract}

\section{Introduction}

The incidence and mortality rates of lung cancer have increased globally during the last few decades $(1,2)$. The majority of cases of lung cancer diagnosed were non-small cell lung cancer (NSCLC), and $40 \%$ of patients with NSCLC are affected by advanced diseases (3). For patients with advanced NSCLC with a good performance status, systemic chemotherapy is the standard therapy at present. The first-line treatment for such patients is platinum-based chemotherapy, which improves symptom control, quality of life and survival as compared with best supportive care (4). A good response

Correspondence to: Professor Hiroaki Satoh, Division of Respiratory Medicine, Mito Medical Center, University of Tsukuba, 3-2-7 Miya-machi, Mito, Ibaraki 310-0015, Japan

E-mail: hirosato@md.tsukuba.ac.jp

Key words: non-small cell lung cancer, stable disease, disease control rate, survival [complete response or partial response (CR/PR)] to chemotherapy has typically been equated with the clinical benefit of increased survival (5), but only $20-30 \%$ of patients achieve a good response in previous clinical trials, while 40-50\% maintain a stable disease (SD) status (6-8). Certain previous studies reported that an initial good response and stable disease indicate similar survival benefits for chemotherapeutical patients with advanced NSCLC $(9,10)$. The present retrospective study was undertaken to evaluate the similar survival benefits of a good response and stable disease to platinum-based chemotherapy in previously untreated NSCLC patients.

\section{Patients and methods}

Patients. The patients enrolled in the present study were those consecutively diagnosed with NSCLC and treated with platinum-based chemotherapy as first-line treatment at the University of Tsukuba Hospital and Tsukuba Medical Center Hospital (both Tsukuba, Ibaraki, Japan) between January 1999 and December 2012. All the patients were histologically/cytologically confirmed as presenting with NSCLC and unresectable advanced disease. The histopathological diagnosis was defined by the World Health Organization classification (11), and patients were staged according to the Union for International Cancer Control tumor-node-metastasis system (12).

Treatment and response. Enrolled patients received at least one cycle of cisplatin- or carboplatin-based chemotherapy. The clinical, pathological and radiological data, and the follow-up information obtained until May 2013 were retrospectively reviewed. The patient characteristics and efficacy were evaluated using patient data extracted from the database. Tumor responses were classified as a CR, PR, SD, progressive disease (PD) or not evaluable (NE), according to the response evaluation criteria for solid tumors (RECIST) version 1.1 (13). This observational study conformed to the Ethical Guidelines for Clinical Studies issued by the Ministry of Health, Labor and Welfare of Japan.

The progression-free survival (PFS) time of each patient was calculated from the day that chemotherapy was commenced until disease progression. Overall survival (OS) time was 
calculated from the day that chemotherapy was commenced until mortality or the latest follow-up of the patient.

Statistical analysis. The survival rate was analyzed by the Kaplan-Meier method, and comparisons were performed using the log-rank test in univariate analysis. Significant variables identified in the univariate analysis were included in the multivariate survival analysis using Cox proportional hazards model to study the effects of clinicopathological factors on survival. $\mathrm{P}<0.05$ was considered to indicate a statistically significant difference. All statistical analyses were performed using StatView software for Windows, version 5.0 (SAS Institute Inc., Cary, NC, USA).

\section{Results}

Patients. Between January 1999 and December 2012, 322 patients were diagnosed with advanced NSCLC and received platinum-based chemotherapy at two hospitals. The median follow-up period was 10.2 months (range, 0.7-134.0 months). Table I shows the patient characteristics. Of the 322 patients, 234 were male, and the median age was 64 years (range, 21-88 years). In total, 85 patients were never-smokers. With regard to performance status (PS), 258 patients exhibited a PS of 0-1 and 64 exhibited a PS of 2-4. Overall, 33 patients presented with stage IIIA-B disease and 289 patients with stage IV. Of the 322 NSCLC cases, 246 (76.4\%) were adenocarcinoma, $62(19.3 \%)$ were squamous cell carcinoma, 11 (3.4\%) were large cell carcinoma, and $3(0.9 \%)$ were other types. Epidermal growth factor receptor (EGFR) mutation positivity was found in 19 patients, while 69 patients were negative for the mutation and 234 patients were not evaluated for EGFR. The chemotherapy regimens used are presented in Table II; 105 (32.6\%) patients were administered cisplatin-based chemotherapy, and 217 (67.4\%) patients were administered carboplatin-based chemotherapy as first-line treatment. In the platinum-based chemotherapy regimens [carboplatin (area under the serum concentration-time curve, $4-5 \mathrm{mg} / \mathrm{ml} / \mathrm{min}$; day 1 ; 3-4-week cycle) and cisplatin $\left(60-80 \mathrm{mg} / \mathrm{m}^{2}\right.$; day $1,3-4$-week cycle)], the cytotoxic drugs such as paclitaxel $\left(180-200 \mathrm{mg} / \mathrm{m}^{2}\right.$; day $1 ; 3-4$-week cycle), doctaxel $\left(60 \mathrm{mg} / \mathrm{m}^{2}\right.$; day $1 ; 3-4$-week cycle), gemcitabine $\left(1000 \mathrm{mg} / \mathrm{m}^{2}\right.$; days 1 and $8 ; 3-4$-week cycle) and pemetrexed $\left(500 \mathrm{mg} / \mathrm{m}^{2}\right.$; day $1 ; 3$-4-week cycle) were administered in 95, 62, 47 and 43 patients, respectively. The median number of cycles of platinum-based chemotherapy was 2 (range, 1-7 cycles), and the median number of cycles of maintenance therapy was 3 (range, 1-12 cycles).

Responseldisease control and survival. The median OS time for the 322 patients was 11.7 months. A total of 67 (20.8\%) patients were responders (no CR and 67 PR) and 165 (51.2\%) patients achieved SD, which amounted to a disease control rate (DCR) of $72.0 \%$. In the 260 patients with non-squamous cell carcinoma, 50 (19.2\%) were responders (no CR and $50 \mathrm{PR}$ ) and 135 (51.9\%) achieved SD, which amounted to a DCR of $71.1 \%$. In the 62 patients with squamous cell carcinoma, 17 (27.4\%) were responders (no CR and $17 \mathrm{PR}$ ) and 30 (48.4\%) patients achieved SD, which amounted to a DCR of $75.8 \%$.

As shown in Fig. 1, the median OS time in the 232 patients with CR/PR or SD was better than that of the 90 patients with
Table I. Characteristics of 322 patients with non-small cell lung cancer who received platinum-based chemotherapy.

\begin{tabular}{|c|c|}
\hline Characteristic & Value \\
\hline Median age (range), years & $64(21-88)$ \\
\hline \multicolumn{2}{|l|}{ Gender, n (\%) } \\
\hline Male & $234(72.7)$ \\
\hline Female & $88(27.3)$ \\
\hline \multicolumn{2}{|l|}{ Smoking status, n (\%) } \\
\hline Smoker & $237(73.6)$ \\
\hline Never-smoker & $85(26.4)$ \\
\hline \multicolumn{2}{|l|}{ Performance status, n (\%) } \\
\hline $0-1$ & $258(80.1)$ \\
\hline $2-4$ & $64(19.9)$ \\
\hline \multicolumn{2}{|l|}{ Clinical stage, n (\%) } \\
\hline IIIA-B & $33(10.2)$ \\
\hline IV & $289(89.8)$ \\
\hline \multicolumn{2}{|l|}{ Pathology, n (\%) } \\
\hline Adenocarcinoma & $246(76.4)$ \\
\hline Squamous cell carcinoma & $62(19.3)$ \\
\hline Large cell carcinoma & $11(3.4)$ \\
\hline Other & $3(0.9)$ \\
\hline \multicolumn{2}{|l|}{ EGFR mutation, n (\%) } \\
\hline Positive & $19(5.9)$ \\
\hline Negative & $69(21.4)$ \\
\hline Not evaluated & $234(72.7)$ \\
\hline
\end{tabular}

EGFR, epidermal growth factor receptor.

PD (14.6 vs. 5.1 months; $\mathrm{P}<0.001)$. By contrast, there was no difference in PFS time between the 67 patients with $\mathrm{CR} / \mathrm{PR}$ and the 165 patients with SD (6.8 vs. 5.5 months; $\mathrm{P}=0.347)$ (Fig. 2). There was also no significant difference between patients with $\mathrm{CR} / \mathrm{PR}$ and those with $\mathrm{SD}$ with regard to OS time (15.6 vs. 14.3 months; $\mathrm{P}=0.878$ ) (Fig. 3).

In the patients with non-squamous cell carcinoma, the median OS time in the patients with CR/PR and SD was better than that in the patients with $\mathrm{PD}$ (16.1 vs. 5.2 months; $\mathrm{P}<0.001$ ). There was no difference in PFS time between the patients with $\mathrm{CR} / \mathrm{PR}$ and the patients with SD (7.3 vs. 5.7 months; $\mathrm{P}=0.253$ ). Additionally, there was no significant difference between the patients with $\mathrm{CR} / \mathrm{PR}$ and those with $\mathrm{SD}$ with regard to $\mathrm{OS}$ (16.9 vs. 15.1 months; $\mathrm{P}=0.938$ ).

In the patients with squamous cell carcinoma, the OS time in the patients with CR/PR and SD was better than that in the patients with PD (13.1 vs. 4.8 months; $\mathrm{P}<0.001)$. There was no difference in PFS time between the patients with CR/PR and the patients with SD (5.0 vs. 5.1 months; $\mathrm{P}=0.978$ ). Also, there was no significant difference between the patients with $\mathrm{CR} / \mathrm{PR}$ and those with $\mathrm{SD}$ with regard to $\mathrm{OS}$ time (13.1 vs. 13.3 months; $\mathrm{P}=0.732$ ).

Prognostic factors. Next, the prognostic factors of the 322 NSCLC patients were evaluated. Table III presents the results of the univariate and multivariate analyses. In the 
Table II. Regimens of chemotherapy.

\begin{tabular}{lc}
\hline Regimen & Value \\
\hline Platinum, n (\%) & \\
Cisplatin & $105(32.6)$ \\
Carboplatin & $217(67.4)$ \\
Combined drugs, n (\%) & \\
Paclitaxel & $95(29.5)$ \\
Docetaxel & $62(19.3)$ \\
Gemcitabine & $47(14.6)$ \\
Pemetrexed & $43(13.4)$ \\
Vinorelbine & $38(11.8)$ \\
S-1 & $13(4.0)$ \\
Etoposide & $12(3.7)$ \\
Vindesine & $11(3.4)$ \\
Bevacizumab & $11(3.4)$ \\
Irinotecan & $3(0.9)$ \\
Median number of platinum-based & $2(1-7)$ \\
chemotherapy cycles (range) & \\
Median number of maintenance & \\
therapy cycles (range) & $3(1-12)$ \\
\hline
\end{tabular}

univariate analysis, the female gender, a good PS (PS of 0-1), never-smoker status, non-squamous cell carcinoma, cisplatin-based chemotherapy, pemetrexed-containing chemotherapy, bevacizumab-containing chemotherapy and disease-controlled patients (CR/PR and SD) were associated with a longer OS time. According to the multivariate Cox proportional hazards model, a good PS (PS of 0-1), never-smoker status, pemetrexed-containing chemotherapy and disease-controlled patients (CR/PR and SD) were favorable prognostic factors.

\section{Discussion}

In the present study evaluating daily practice in NSCLC patients, four main results were found. First, in the overall group of NSCLC patients, the DCR (CR/PR and SD rates) was $72.0 \%$, although the response rate that was composed of CR/PR alone was only $20.8 \%$. Second, the OS time was 11.7 months in the overall group of NSCLC patients, and 14.6 months in the disease-controlled patients (patients with CR, PR and SD). Third, the OS time in the disease-controlled patients was longer than that in the patients with PD, but there was no statistical significant difference in the OS time between the patients with CR/PR and those with SD. The same results were observed in the patients with squamous cell lung carcinoma and those with non-squamous cell carcinoma. Fourth, the OS time in the disease-controlled patients treated with platinum and pemetrexed was 21.4 months.

Thus, these results illustrated that prolongation of survival time was associated not with the response rate, but with the disease control rate, and a high response rate may have scarce clinical meaning in daily practice. If a cure would not be achieved, these results implied that it would be

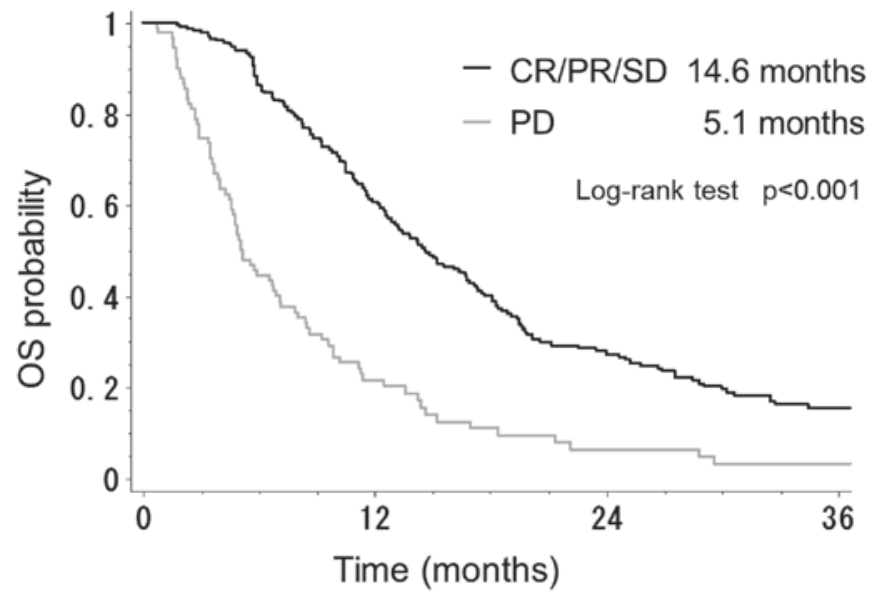

Figure 1. OS in non-small cell lung cancer patients with a CR/PR/SD or PD. Patients with $\mathrm{CR} / \mathrm{PR} / \mathrm{SD}$ had a significantly better prognosis compared with patients with PD (median OS, 14.6 vs. 5.1 months; $\mathrm{P}<0.001$ ). OS, overall survival; CR, complete response; $\mathrm{PR}$, partial response; $\mathrm{SD}$, stable disease; PD, progressive disease.

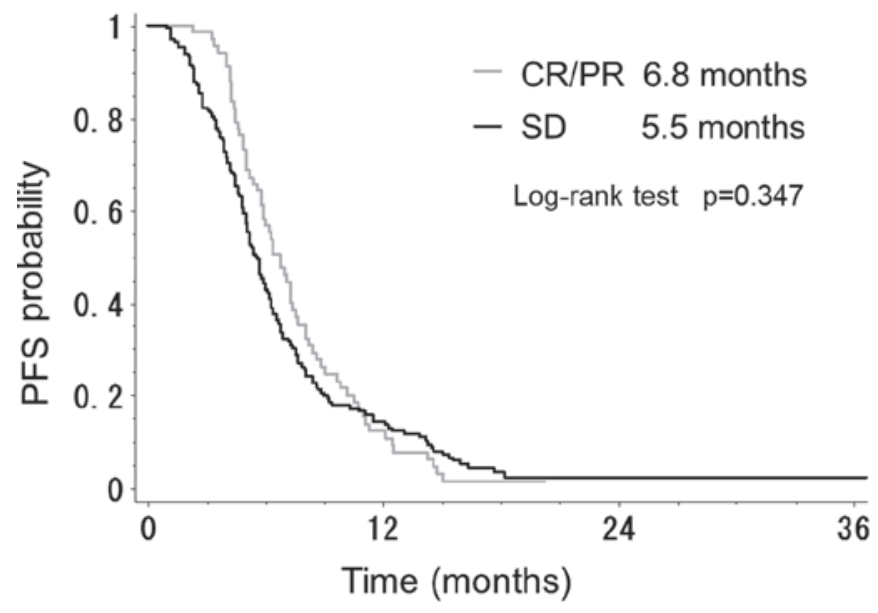

Figure 2. PFS in non-small cell lung cancer patients with CR/PR or SD No significant difference was identified between the patients with CR/PR and SD (median PFS, 6.8 vs. 5.5 months; $\mathrm{P}=0.347$ ). PFS, progression-free survival; CR, complete response; $\mathrm{PR}$, partial response; $\mathrm{SD}$, stable disease.

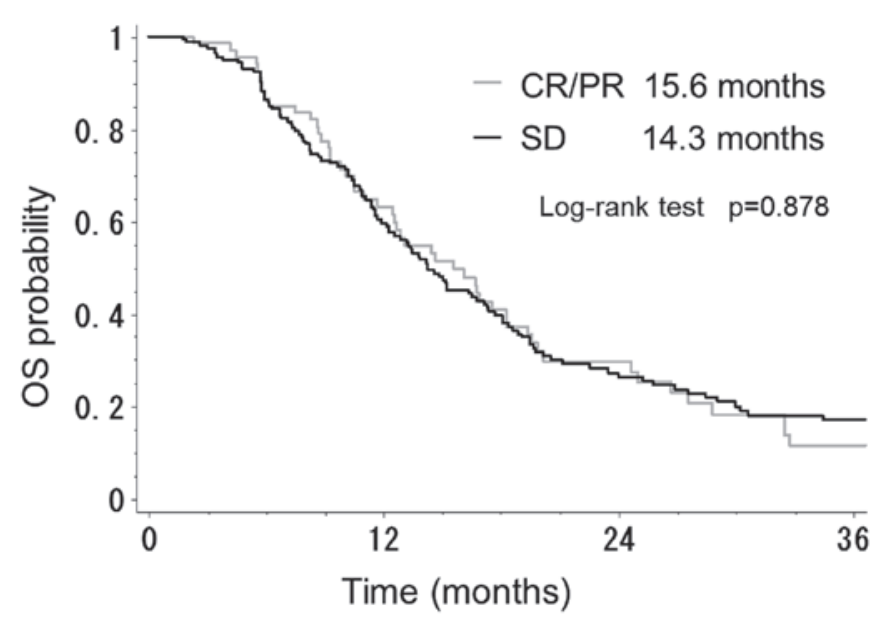

Figure 3. OS in non-small cell lung cancer patients patient with CR/PR or SD. No significant difference was identified between patients with CR/PR and SD (median OS, 15.6 months vs. 14.3 months, $\mathrm{P}=0.878$ ). OS, overall survival; CR, complete response; $\mathrm{PR}$, partial response; $\mathrm{SD}$, stable disease. 
Table III. Prognostic factors of the 322 non-small cell lung cancer patients.

A, Univariate survival analysis (log-rank test)

\begin{tabular}{lrr}
\hline Prognostic factors & Median OS time, months & P-value \\
\hline Gender (female/male) & $16.7 / 10.9$ & $<0.001$ \\
Age, years (<70/ $\geq 70)$ & $11.2 / 13.3$ & 0.528 \\
PS (0-1/2-4) & $13.6 / 5.8$ & $<0.001$ \\
Smoking status (never-smoker/smoker) & $18.1 / 11.0$ & $<0.001$ \\
Non-squamous/squamous cell carcinoma & $12.3 / 10.5$ & 0.046 \\
CDDP/CBDCA & $13.5 / 11.4$ & 0.041 \\
PEM (+/-) & $21.4 / 10.2$ & $<0.001$ \\
Bevacizumab (+/-) & $21.4 / 11.3$ & 0.004 \\
Maintenance (+/-) & $18.1 / 11.6$ & 0.191 \\
CR+PR/SD+PD & $15.6 / 11.2$ & 0.064 \\
CR+PR+SD/PD & $14.6 / 5.1$ & $<0.001$ \\
\hline
\end{tabular}

B, Multivariate analysis (Cox's proportional hazards model)

\begin{tabular}{lccc}
\hline Prognostic factors & Hazard ratio & $95 \%$ CI & P-value \\
\hline Female & 0.75 & $0.52-1.07$ & 0.106 \\
PS 0-1 & 0.48 & $0.35-0.66$ & $<0.001$ \\
Never-smoker & 0.64 & $0.44-0.93$ & 0.020 \\
Non-squamous cell carcinoma & 0.98 & $0.71-1.36$ & 0.896 \\
CDDP & 0.95 & $0.71-1.27$ & 0.722 \\
PEM & 0.47 & $0.32-0.68$ & $<0.001$ \\
Bevacizumab & 0.60 & $0.32-1.14$ & 0.117 \\
CR+PR+SD & 0.37 & $0.28-0.48$ & $<0.001$ \\
\hline
\end{tabular}

CDDP, cisplatin; CBDCA, carboplatin; PEM, pemetrexed; CR, complete response; PR, partial response; SD, stable disease; PD, progressive disease; CI, confidence interval.

important not to merely achieve shrinkage of the tumor, but to maintain the patent's condition for a long time without any tumor progression.

In previous studies, there have been various opinions with regard to the survival of patients with $\mathrm{SD}$; certain studies have insisted that patients with SD were associated with a favorable, long OS time compared with those with CR/PR $(9,10)$, and another study described a longer OS time obtained in patients with CR/PR compared with those with SD (14). Lara et al (9) suggested that patients who achieved SD at 8 weeks experience a survival time equal to that of PR/CR patients. The study claimed that DCR (CR, PR and SD) is stronger than response (CR/PR alone) in the prediction of the OS time of patients with advanced NSCLC. He et al (10) reported that initial CR/PR and SD result in similar PFS and OS times for patients with advanced NSCLC receiving platinum-based chemotherapy. One previous study suggested that SD may be representative of a potential survival benefit of chemotherapy. Therefore, the differentiation between SD and CR/PR may not be of any practical importance (15). By contrast, Coudert et al (14) reported that SD after first-line chemotherapy was a significant negative prognostic factor compared with CR/PR.
Recently, Mandrekar et al (16) indicated that patients with PD experienced worse survival compared with those with non-PD, with a certain degree of separation between the NSCLC categories of SD and CR/PR. Controversy remains with regard to whether initial $\mathrm{CR} / \mathrm{PR}$ and $\mathrm{SD}$ indicate similar survival benefits or not in advanced NSCLC patients receiving chemotherapy. This may be due to the complexity of SD that exhibits minor increases and decreases: When SD is achieved, some patients experience tumor shrinkage of $<30 \%$ in the diameter of the target lesions, whilst others experience tumor increases of $<20 \%$ in the diameter of the target lesions. These 'decreased' SD and 'increased' SD may have different behavior. In the present patients, there was no statistical significant difference in survival time between the patients with SD and those with CR/PR.

In clinical trials and in practice, prolongation of survival time appears to have been recorded in NSCLC patients in recent years, which may have been due to the appearance of more effective and less toxic drugs (17), molecular targeting agents (18-22) and the improvement of supportive therapy, such as G-CSF (23) and antiemetic drugs (24). In the present study, the survival of all consecutive NSCLC patients in daily 
practice was evaluated, therefore, the study included 'unfit' patients, who are usually excluded from clinical trials. However, it was notable that the OS time in these patients was not shorter than that observed in recent clinical trials (25-30). In addition, in the present patients treated with platinum and pemetrexed, the OS time was as long as that observed in the PARAMOUNT trial (16.9 months) (31). In patients treated with bevacizumab and those with maintenance therapy with the drug, the OS time in the present study was evaluated to be as good as that of previous clinical trials (32-33). Our 'daily clinical practice' results provide information for the near future treatment of NSCLC patients. We believe that these favorable results are largely dependent on the power of novel antitumor drugs, such as pemetrexed, tyrosine kinase inhibitors and bevacizumab.

Despite these significant findings, the present study has certain limitations. The first limitation was inherent to the retrospective design of the study: lead time and length time biases could not be avoided. Second, OS time may have been affected by other factors, such as the effects of second-line and subsequent therapies. Third, the study period was so long that various regimens were enrolled. Not only novel antitumor drugs, but also improvements in supportive care and advances in imaging techniques may have conferred favorable effects for the survival of patients in recent years. Fourth, the RECIST criteria were not always applied to clinical chemotherapy decisions in daily practice. If SD is achieved in daily practice, careful consideration is required to decide whether or not to continue the chemotherapy using the same regimen.

Regardless of these limitations, the findings of the present study have certain clinical significance for the management of future NSCLC patients of unselected groups. The results confirmed that careful consideration is required in treating NSCLC patients who experience SD with chemotherapy.

In conclusion, if the primary outcome of chemotherapy for NSCLC at present is not shrinkage of the tumor, but is the prolongation of survival, chemotherapy would provide a clinical benefit not only for the $20 \%$ of patients with a good response who have CR/PR, but also for the $70 \%$ of disease-controlled patients who have SD, PR and CR.

\section{References}

1. Kamangar F, Dores GM and Anderson WF: Patterns of cancer incidence, mortality and prevalence across five continents: Defining priorities to reduce cancer disparities in different geographic regions of the world. J Clin Oncol 24: 2137-2150, 2006.

2. Jemal A, Center MM, DeSantis C and Ward EM: Global patterns of cancer incidence and mortality rates and trends. Cancer Epidemiol Biomarkers Prev 19: 1893-1907, 2010.

3. Little AG, Gay EG, Gaspar LE and Stewart AK: National survey of non-small cell lung cancer in the United States: Epidemiology, pathology and patterns of care. Lung Cancer 57: 253-260, 2007.

4. Ramalingam S and Belani C: Systemic chemotherapy for advanced non-small cell lung cancer: Recent advances and future directions. Oncologist 13 (Suppl 1): 5-13, 2008.

5. Therasse P: Measuring the clinical response. What does it mean? Eur J Cancer 38: 1817-1823, 2002.

6. Kelly K, Crowley J, Bunn PA Jr, et al: Randomized phase III trial of paclitaxel plus carboplatin versus vinorelbine plus cisplatin in the treatment of patients with advanced non-small-cell lung cancer: A Southwest Oncology Group trial. J Clin Oncol 19: 3210-3218, 2001

7. Yamamoto N, Nambu Y, Fujimoto T and Koshiji M: A landmark point analysis with cytotoxic agents for advanced NSCLC. J Thorac Oncol 4: 697-701, 2009.
8. Paz-Ares L, de Marinis F, Dediu M, Thomas M, Pujol JL, Bidoli P, Molinier O, Sahoo TP, Laack E, Reck M, et al: Maintenance therapy with pemetrexed plus best supportive care versus placebo plus best supportive care after induction therapy with pemetrexed plus cisplatin for advanced non-squamous non-small-cell lung cancer (PARAMOUNT): A double-blind, phase 3, randomised controlled trial. Lancet Oncol 13: 247-255, 2012.

9. Lara PN Jr, Redman MW, Kelly K, Edelman MJ, Williamson SK, Crowley JJ and Gandara DR; Southwest Oncology Group: Disease control rate at 8 weeks predicts clinical benefit in advanced non-small-cell lung cancer: Results from Southwest Oncology Group randomized trials. J Clin Oncol 26: 463-467, 2008.

10. He L, Teng Y, Jin B, Zhao M, Yu P, Hu X, Zhang J, Li S, Gao Y and Liu Y: Initial partial response and stable disease according to RECIST indicate similar survival for chemotherapeutical patients with advanced non-small cell lung cancer. BMC Cancer 10: 681, 2010.

11. Travis WD, Colby TV and Sobin LH (eds): Histological classification of lung and pleural tumours. In: World Health Organization - International Histological Classification of Tumours: Histological Typing of Lung and Pleural Tumours. 3rd edition. Springer, Geneva, pp21-24, 1999.

12. Goldstraw P, Crowley J, Chansky K, Giroux DJ, Groome PA, Rami-Porta R, Postmus PE, Rusch V and Sobin L; International Association for the Study of Lung Cancer International Staging Committee; Participating Institutions: The IASLC Lung Cancer Staging Project: proposals for the revision of the TNM stage groupings in the forthcoming (seventh) edition of the TNM Classification of malignant tumours. J Thorac Oncol 2: 706-714, 2007.

13. Eisenhauer EA, Therasse P, Bogaerts J, Schwartz LH, Sargent D, Ford R, Dancey J, Arbuck S, Gwyther S, Mooney M, et al: New response evaluation criteria in solid tumours: Revised RECIST guideline (version 1.1). Eur J Cancer 45: 228-247, 2009.

14. Coudert B, Ciuleanu T, Park K, Wu YL, Giaccone G, Brugger W, Gopalakrishna P and Cappuzzo F; SATURN Investigators: Survival benefit with erlotinib maintenance therapy in patients with advanced non-small-cell lung cancer (NSCLC) according to response to first-line chemotherapy. Ann Oncol 23: 388-394, 2012.

15. Cesano A, Lane SR, Ross GA and Fields SZ: Stabilization of disease as an indicator of clinical benefit associated with chemotherapy in non-small cell lung cancer patients. Int J Oncol 17: 587-590, 2000.

16. Mandrekar SJ, An MW, Meyers J, Grothey A, Bogaerts J and Sargent DJ: Evaluation of alternate categorical tumor metrics and cut points for response categorization using the RECIST 1.1 data warehouse. J Clin Oncol 32: 841-850, 2014.

17. Ho C, Ramsden K, Zhai Y, Murray N, Sun S, Melosky B and Laskin J: Less toxic chemotherapy improves uptake of all lines of chemotherapy in advanced non-small-cell lung cancer: A 10-year retrospective population-based review. J Thorac Oncol 9: 1180-1186, 2014

18. Maemondo M, Inoue A, Kobayashi K, Sugawara S, Oizumi S, Isobe H, Gemma A, Harada M, Yoshizawa H, Kinoshita I, et al: Gefitinib or chemotherapy for non-small-cell lung cancer with mutated EGFR. N Engl J Med 362: 2380-2388, 2010.

19. Mitsudomi T, Morita S, Yatabe Y,Negoro S, Okamoto I, Tsurutani J, Seto T, Satouchi M, Tada H, Hirashima T, et al: Gefitinib versus cisplatin plus docetaxel in patients with non-small-cell lung cancer harbouring mutations of the epidermal growth factor receptor (WJTOG3405): An open label, randomised phase 3 trial. Lancet Oncol 11: 121-128, 2010.

20. Zhou C, Wu YL, Chen G, Feng J,Liu XQ, Wang C, Zhang S, Wang J, Zhou S, Ren S, et al: Erlotinib versus chemotherapy as first-line treatment for patients with advanced EGFR mutation-positive non-small-cell lung cancer (OPTIMAL, CTONG-0802): A multicentre, open-label, randomised, phase 3 study. Lancet Oncol 12: 735-742, 2011.

21. Rosell R, Carcereny E, Gervais R, et al; Spanish Lung Cancer Group in collaboration with Groupe Français de Pneumo-Cancérologie and Associazione Italiana Oncologia Toracica: Erlotinib versus standard chemotherapy as first-line treatment for European patients with advanced EGFR mutation-positive non-small-cell lung cancer (EURTAC): A multicentre, open-label, randomised phase 3 trial. Lancet Oncol 13: 239-246, 2012

22. Yang JC, Wu YL, Schuler M, M, Popat S, Yamamoto N, Zhou C, Hu CP, O'Byrne K, Feng J, et al: Afatinib versus cisplatin-based chemotherapy for EGFR mutation-positive lung adenocarcinoma (LUX-Lung 3 and LUX-Lung 6): Analysis of overall survival data from two randomised, phase 3 trials. Lancet Oncol 16: 141-151, 2015. 
23. Lyman GH, Reiner M, Morrow PK and Crawford J: The effect of filgrastim or pegfilgrastim on survival outcomes of patients with cancer receiving myelosuppressive chemotherapy. Ann Oncol: Apr 7, 2015. pii: mdv174 (Epub ahead of print).

24. Uchino J, Hirano R, Tashiro N, Yoshida Y, Ushijima S, Matsumoto T, Ohta K, Nakatomi K, Takayama K, Fujita M, et al: Efficacy of aprepitant in patients with advanced or recurrent lung cancer receiving moderately emetogenic chemotherapy. Asian Pac J Cancer Prev 13: 4187-4190, 2012.

25. Fossella F, Pereira JR, von Pawel J, Pluzanska A, Gorbounova V, Kaukel E, Mattson KV, Ramlau R, Szczesna A, Fidias P, et al: Randomized, multinational, phase III study of docetaxel plus platinum combinations versus vinorelbine plus cisplatin for advanced non-small-cell lung cancer: The TAX 326 study group. J Clin Oncol 21: 3016-3024, 2003.

26. Ohe Y, Ohashi Y, Kubota K, Tamura T, Nakagawa K, Negoro S, Nishiwaki Y, Saijo N, Ariyoshi Y and Fukuoka M: Randomized phase III study of cisplatin plus irinotecan versus carboplatin plus paclitaxel, cisplatin plus gemcitabine and cisplatin plus vinorelbine for advanced non-small-cell lung cancer: Four-Arm Cooperative Study in Japan. Ann Oncol 18: 317-323, 2007.

27. Fidias PM, Dakhil SR, Lyss AP, Loesch DM, Waterhouse DM, Bromund JL, Chen R, Hristova-Kazmierski M, Treat J, Obasaju CK, et al: Phase III study of immediate compared with delayed docetaxel after front-line therapy with gemcitabine plus carboplatin in advanced non-small-cell lung cancer. J Clin Oncol 27: 591-598, 2009.

28. Ciuleanu T, Brodowicz T, Zielinski C, Kim JH, Krzakowski M, Laack E, Wu YL, Bover I, Begbie S, Tzekova V, et al: Maintenance pemetrexed plus best supportive care versus placebo plus best supportive care for non-small-cell lung cancer: A randomised, double-blind, phase 3 study. Lancet 374: 1432-1440, 2009.
29. Cappuzzo F, Ciuleanu T, Stelmakh L, Cicenas S, Szczésna A Juhász E, Esteban E, Molinier O, Brugger W, Melezínek I, et al: Erlotinib as maintenance treatment in advanced non-small-cell lung cancer: A multicentre, randomised, placebo-controlled phase 3 study. Lancet Oncol 11: 521-529, 2010.

30. Pérol M, Chouaid C, Pérol D, Barlési F, Gervais R, Westeel V, Crequit J, Léna H, Vergnenègre A,Zalcman G, et al: Randomized, phase III study of gemcitabine or erlotinib maintenance therapy versus observation, with predefined second-line treatment, after cisplatin-gemcitabine induction chemotherapy in advanced non-small-cell lung cancer. J Clin Oncol 30: 3516-3524, 2012.

31. Paz-Ares LG, de Marinis F, Dediu M, Thomas M,Pujol JL, Bidoli P, Molinier O, Sahoo TP, Laack E, Reck M, et al: PARAMOUNT: Final overall survival results of the phase III study of maintenance pemetrexed versus placebo immediately after induction treatment with pemetrexed plus cisplatin for advanced nonsquamous non-small-cell lung cancer. J Clin Oncol 31: 2895-2902, 2013.

32. Sandler A, Gray R, Perry MC, Brahmer J, Schiller JH, Dowlati A, Lilenbaum R and Johnson DH: Paclitaxel-carboplatin alone or with bevacizumab for non-small-cell lung cancer. N Engl J Med 355: 2542-2550, 2006.

33. Barlesi F, Scherpereel A, Gorbunova V, Gervais R, Vikström A, Chouaid C, Chella A, Kim JH, Ahn MJ, Reck M, et al: Maintenance bevacizumab-pemetrexed after first-line cisplatin-pemetrexed-bevacizumab for advanced nonsquamous nonsmall-cell lung cancer: Updated survival analysis of the AVAPERL (MO22089) randomized phase III trial. Ann Oncol 25: 1044-1052, 2014 